\title{
Evaluation The Water Availability in the Dengkeng River Due To Landuse and Climate Changes
}

\author{
Anik Sarminingsih ${ }^{1}$, Dwi Siwi Handayani ${ }^{2}$, Endro Sutrisno ${ }^{3}$, Badrus Zaman ${ }^{4}$ \\ 1,2,3,4 Department of Environmental Engineering, Diponegoro University, Semarang - Indonesia
}

\begin{abstract}
The changes in both climate and land cover have some impact on water resources. Dengkeng watershed, mostly located in Klaten district of Central Java Province. Dengkeng River as one of the raw water source of agriculture and drinking water of society, besides as main water body in the drainage system. Climate change and land use directly affect land use patterns, water availability, flood control performance, local social and economic development, and so on. Therefore, studying the impacts of climate change and land use becomes very important. The HEC-HMS model is used in this study. The observed discharge data used AWLR data of Paseban with period 2005-2017, climate data used nearest post data with observation period 1979-2014. While changes in land use were used data in 1990, 2000 and 2011. The results of the analysis on climate change showed an increase in rainfall both monthly rainfall and maximum daily rainfall. While land use changes can be reviewed on the watershed hydrological parameters, one of which is the change of Curve Number $(\mathrm{CN})$. An increase in $\mathrm{CN}$ value has an impact on increasing runoff. However, if viewed against the availability of water, then there is a trend of decline.
\end{abstract}

Keywords: land use; climate, water availability.

\section{Introduction}

Climate change and land use are closely related. Increased carbon emissions are alleged as one of the causes of accelerating climate change. Population development increases the need for land and various other aspects of life. Conversion of land use from forests to built areas on the side of benefits will increase the economy but on the other hand, will increase carbon emissions. Therefore, in spatial planning, it is necessary to pay attention to the impact that has been caused by the possibility of carbon emissions. Changes in spatial planning besides having an impact on carbon emissions also affect the hydrological conditions of a watershed. Hydrological changes will affect the potential of existing water resources.

The aim of study is to evaluate the trend of flood discharge and low discharge due to landuse changing. The evaluation approaches used a hydrological model with HEC-HMS..

In the las few decades, studies on climate change have been intensively carried out in various contries. This is because of almost all countries begin to feel the effects of climate change both regionally and locally. Some impacts related to watershed hydrologal parameter include changes in the duration and intensity of rainfall.

\section{Purpose of the Study}

The purpose of this research is to evaluate the trend of flood dishcarge and water avalilability due to land use changing. The other objective is to know is the climate changing also happen in Dengkeng Watershed. The hydrological parameter is estimated using HEC HMS, using relation rainfall-runoff.

\section{Method of Study}

The methodology can be divided into four major tasks: (1) obtaining the geographic locations of the studied basins; (2) DEM processing, delineating streams and watershed characteristics, terrain processing, and basin processing; (3) importing the processed data to HMS; and (4) merging the observed historical data with the processed DEM for model simulations.[3]

\subsection{The HEC-HMS Model}

In HEC-HMS, rainfall runoff which is happen in the watershed is decribed into six major components i.e meteorological component, loss component, direct runoff component, baseflow component, routing component, and reservoir component.

For developing an HEC-HMS project needed four main contains the hydrologic elements (Sub-basin, reach, junction, reservoir, diversion, source, and sink) and their connectivity that represents the movement of water through the drainage system. Control specifications

\footnotetext{
* Corresponding author: anikharieka@gmail.com
} 
manager is one of the main components of the project and is principally used to control the time interval of simulation.

As the first element for computing is the meteorological component. The meteorological component can be consist of time series of rainfall data and, evapotranspiration data

As input of the model HEC HMS, needed basin rainfall data in the shape of time-series of precipitation data. For calibration a set of time-series of observed discharge data also required. The other input is component of climatological which consist of evapotranspiration. The HEC HMS process generally described in Figure 1.

Sensitivity analysis is useful to see the effect of changing the parameter values of the model results. In this study, sensitivity analisis was carried out on the parameter $o$ curve numbers, with the consideration that curve number have a considerable inluence on the surface runof produced in a watershed.

The calculation method can be used in Table 1 below.

Table 1. Methods Simulation of Dengkeng Watershed.

\begin{tabular}{|c|c|c|}
\hline No & Model & Methods \\
\hline 1 & Precipitation & $\begin{array}{c}\text { User } \\
\text { Hyetograph }\end{array}$ \\
\hline 2 & $\begin{array}{c}\text { Transformati } \\
\text { on }\end{array}$ & SCS's UH \\
\hline 3 & Baseflow & $\begin{array}{c}\text { Exponential } \\
\text { Recession }\end{array}$ \\
\hline 4 & Routing & Lag \\
\hline
\end{tabular}

\subsection{Tools and Material}

Tools and material which are used in this research consist of:

- Daily Rainfall and temperature data were collected from several rainfall stations around Klaten, and temperature data were obtained from meteorological and geophysics agency $(1979-2014)$. These data were used to check for climate trends

- Daily observed flow that was obtained from AWLR in Dengkeng River i.e Jarum.

- Land-use maps in the form of Historical land-use maps were collected from forestry research agency, for periods 1990, 2000, 2011 .

- Map of digital elevation model (90 x 90 m) of Dengkeng Watershe.

- Soil map and it's characteristics that collected from forestry research agency. It was used to obtain

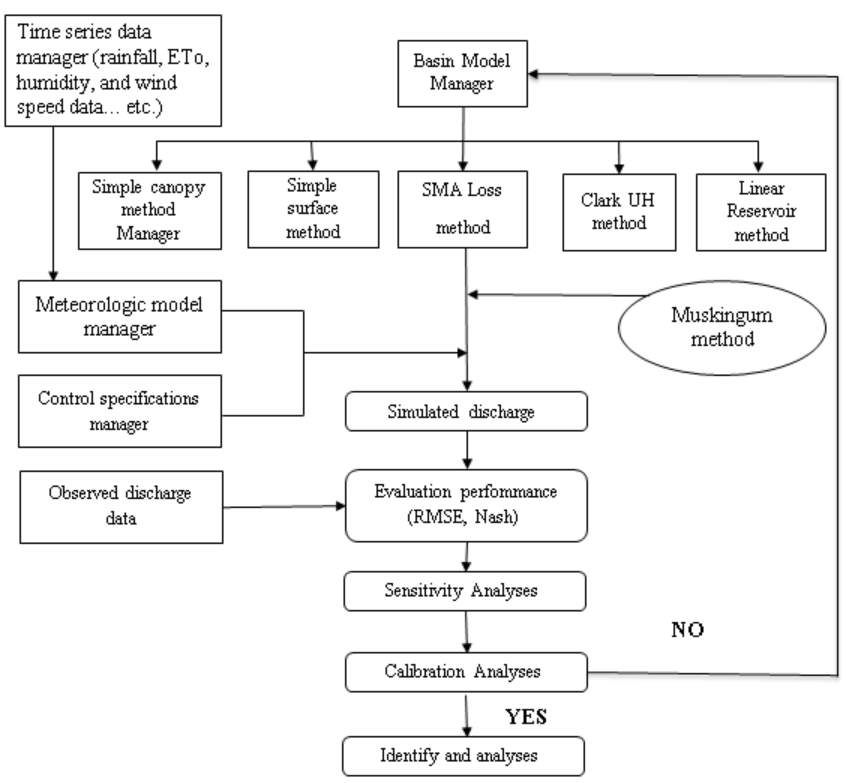

Fig. 1. HEC-HMS Processes

hydrological soil group to determine curve number $(\mathrm{CN})$.

\subsection{Study Field Description}

Dengkeng watershed is one of the sub-watersheds in the upstream Bengawan Solo basin that has an area of about $\pm 828 \mathrm{~km}^{2}$. Geographically located between $110^{\circ} 46$ '42.78' 'BT and $7^{\circ} 40^{\prime} 31.51$ " LS. The length of the river studied in this study is approximately $\pm 45 \mathrm{~km}$ from the mouth of the Dengkeng River upstream, ie at a geographic position of $110^{\circ} 31^{\prime} 50.40^{\prime}$ 'BT and $7^{\circ} 44^{\prime} 31.80$ " LS. Figure 2 shows watershed boundaries and Dengkeng watershed area uses.

Classification of Soil types in Dengkeng watershed consists of 5 (five) kinds, namely: Latosol, Regosol Gray, Grumusol Gray Old, Regosol Complex Gray and Gray, Regosol brown darkness. This soil type as the base of hydrological soil group classification in determining the value of curve number $(\mathrm{CN})$. It is also necessary to estimate the infiltration rate.

Land use data were calculated based on land use maps in 1990, 2000 and 2011. Of the three periods of land use data, the largest land use was in a wetland and slight reductions over the last 20 years. And the second largest land use is a settlement and there is a significant increase. Types of land use and changes that occurred in detail are shown in Table 2. 


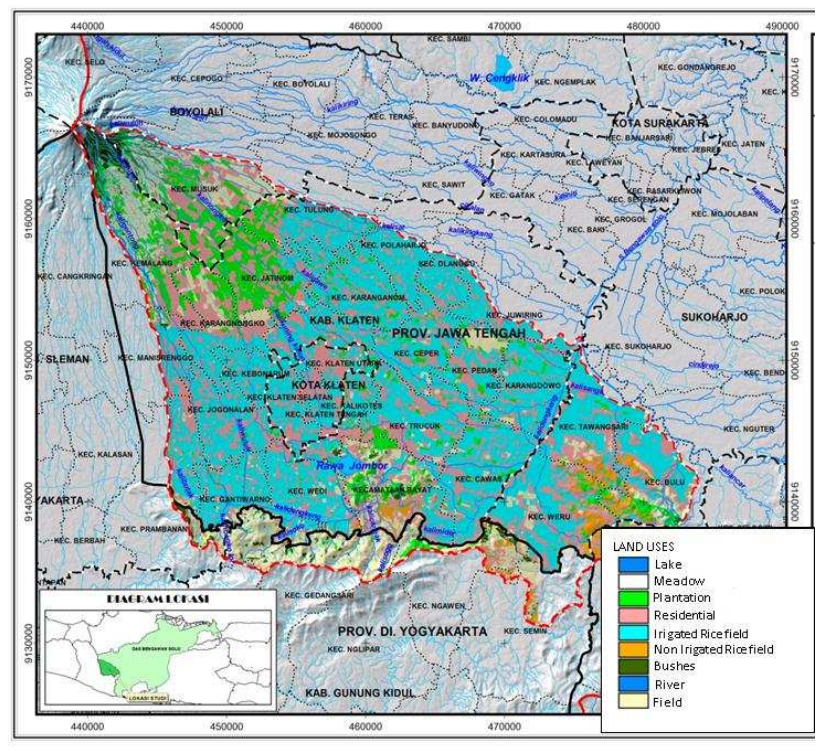

Fig. 2. Catchment Area anad Landuse of Dengkeng Watershed

\subsection{Hydrological Modeling of Dengkeng Watershed}

Modeling of Dengkeng watersheds to AWLR locations of Paseban and tributaries are shown in Figure 3. With the catchment characteristic of each sub-basin, and rainfallrunoff transformation method used SCS method with daily rainfall there can be calculated runoff at any point wanted to be reviewed.

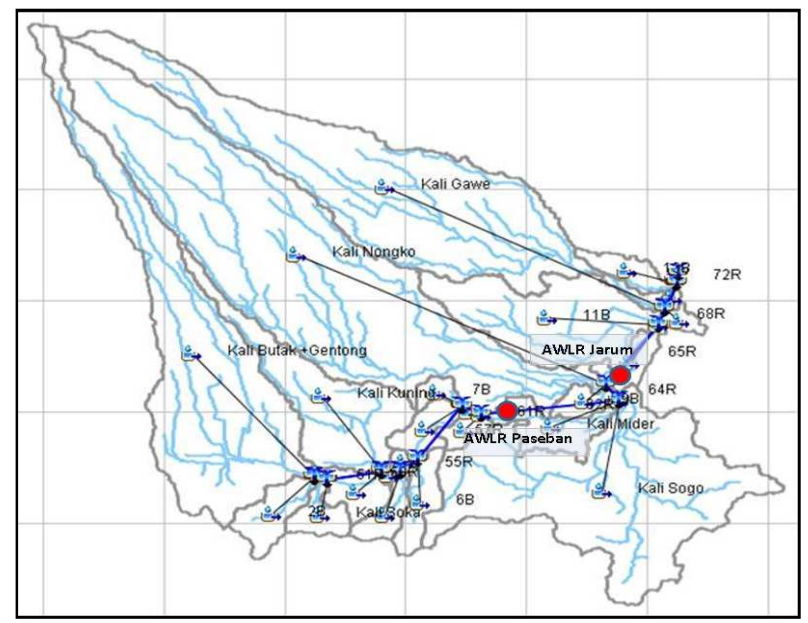

Fig. 3. Hydrological Modeling of Dengkeng Watershed

Table 2. Land uses on Dengkeng Watershed

\begin{tabular}{|c|l|c|c|c|c|c|c|}
\hline \multirow{2}{*}{ NO } & \multirow{2}{*}{ Land Uses } & \multicolumn{3}{|c|}{ AREA (HA) } & \multicolumn{3}{c|}{ Changes (\%) } \\
\cline { 2 - 7 } & $\mathbf{1 9 9 0}$ & $\mathbf{2 0 0 0}$ & $\mathbf{2 0 1 1}$ & $\mathbf{1 9 9 0}$ & $\mathbf{2 0 0 0}$ & $\mathbf{2 0 1 1}$ \\
\hline \multirow{2}{*}{1} & $\begin{array}{l}\text { Secondary } \\
\text { dryland } \\
\text { forest }\end{array}$ & 751 & 692 & 692 & 0.91 & 0.84 & 0.84 \\
\hline
\end{tabular}

\begin{tabular}{|c|l|c|c|c|c|c|c|}
\hline \multirow{2}{*}{ NO } & \multirow{2}{*}{ Land Uses } & \multicolumn{3}{|c|}{ AREA (HA) } & \multicolumn{3}{c|}{ Changes (\%) } \\
\cline { 3 - 8 } & $\mathbf{1 9 9 0}$ & $\mathbf{2 0 0 0}$ & $\mathbf{2 0 1 1}$ & $\mathbf{1 9 9 0}$ & $\mathbf{2 0 0 0}$ & $\mathbf{2 0 1 1}$ \\
\hline 2 & Plantations & 14130 & 14136 & 14144 & 17.05 & 17.06 & 17.07 \\
\hline 3 & Open field & 130 & 132 & 132 & 0.16 & 0.16 & 0.16 \\
\hline 4 & Settlement & 20859 & 20964 & 20992 & 25.17 & 25.30 & 25.33 \\
\hline 5 & $\begin{array}{l}\text { Dryland } \\
\text { farming }\end{array}$ & 3712 & 3675 & 3678 & 4.48 & 4.43 & 4.44 \\
\hline 6 & $\begin{array}{l}\text { Dry land } \\
\text { farms } \\
\text { mixed }\end{array}$ & 7732 & 7732 & 7719 & 9.33 & 9.33 & 9.32 \\
\hline 7 & Rice fields & 35411 & 35331 & 35331 & 42.73 & 42.63 & 42.63 \\
\hline 8 & Shrubs & 2 & 66 & 39 & 0.00 & 0.08 & 0.05 \\
\hline 9 & Water body & 143 & 143 & 143 & 0.17 & 0.17 & 0.17 \\
\hline & TOTAL & 82870 & 82870 & 82870 & 100 & 100 & 100 \\
\hline
\end{tabular}

\subsection{Model Simulations}

Simulation model is carried out when all of components are equipped. The initial simulation is done to ensure model running well. The next step is to do the optimization and sensitivity analisis of curve number component. .

Land-use changes scenario is based on the condition of land cover of 1990, 2000 and 2011 which have the different hydrological parameter. The difference in landuse, type of soil, rainfall depth will afect tne $\mathrm{CN}$ values.

\section{Result And Assessment}

\subsection{Evaluation locally climate change}

One component in evaluating of climate change is the temperatur. Temperatur data in Dengkeng Watershed was collected from nearest meterorological station The impact of climate change is reviewed on the temperature and rainfall changes from the nearest climate station in Dengkeng watershed with data period 1979-2014. As is known, the temperature is an important component in the hydrological process, especially with regard to evaporation and ultimately impacting the overall hydrological process.

Based on climatic data for more than 35 years it is known that there is a trend of increasing the maximum or minimum monthly temperature, as shown in Figure 4.

While in view of the monthly rainfall or maximum daily rainfall, there is an increase in rainfall both in monthly 
rainfall and maximum daily rainfall, with a maximum increase in maximum daily rainfall. As shown in Figure 5.

\subsection{Impact of Climate Land uses}

\subsubsection{Effect of Hydrological Parameter}

The impact of land use is reviewed on changes in rainfall runoff, by simulating the parameters of the hydrology of Dengkeng watershed, to resemble the observed discharge. Based on observational discharge data in AWLR Paseban, with a catchment area of about $213.4 \mathrm{~km} 2$, calibration of watershed hydrological parameters, especially curve number $(\mathrm{CN})$, there is a tendency to increase $\mathrm{CN}$ value, as shown in Figure 6.

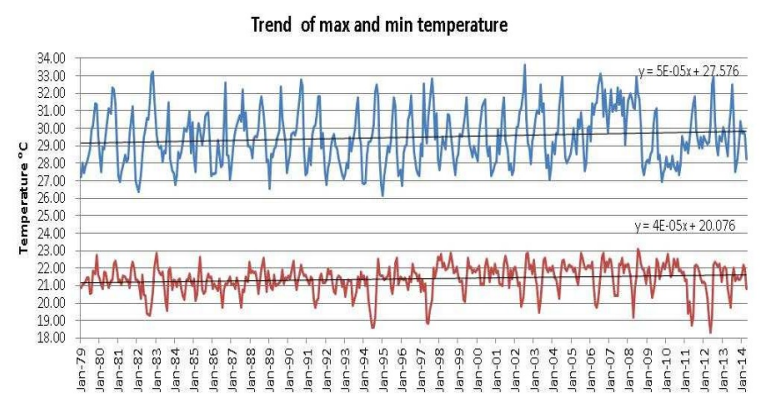

Fig. 4. Trends of Temperature on Dengkeng Watershed

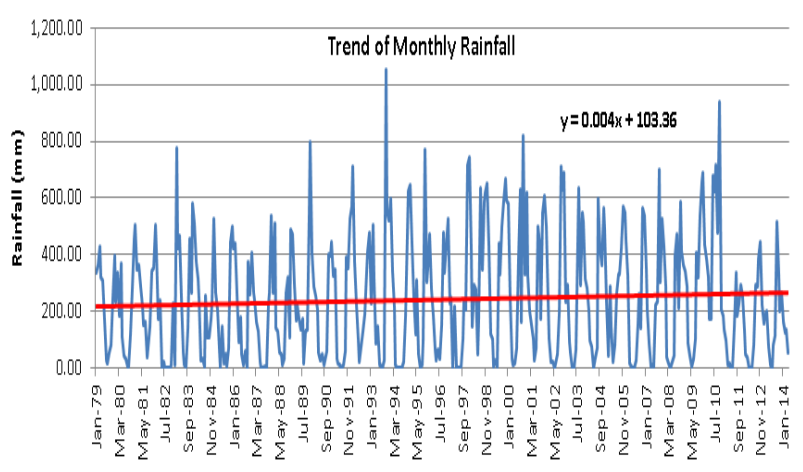

Fig. 5(a)

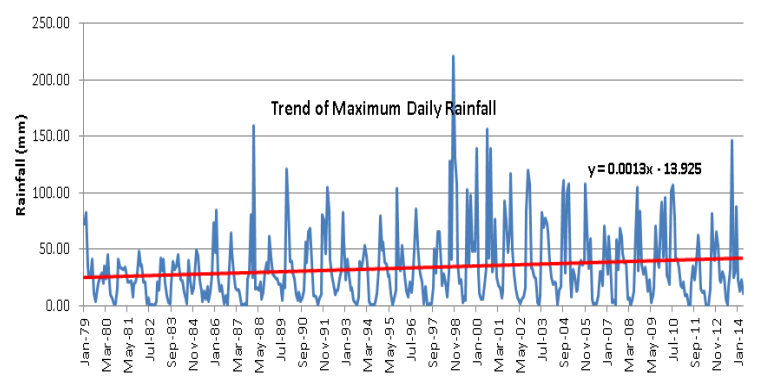

Fig. 5(b)
Fig. 5. Trends of Rainfall on Dengkeng Watershed: (a) Monthly Rainfall, (b) Daily Rainfaal

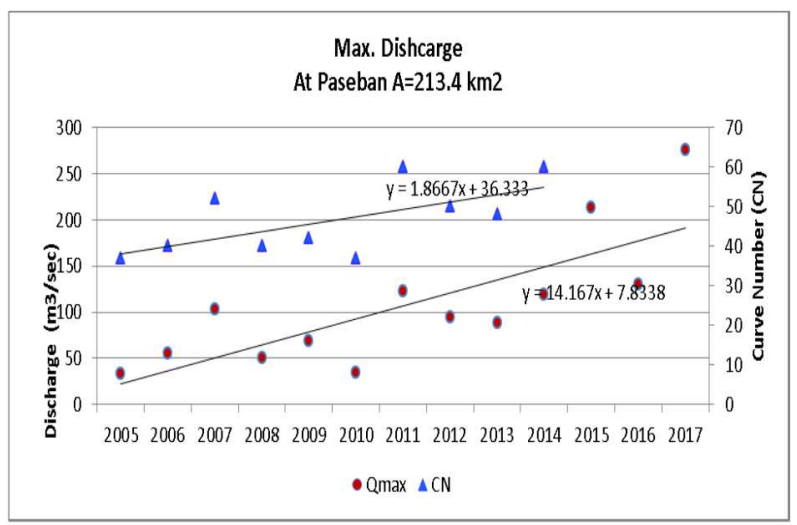

Fig. 6. Trends of Curve Number on Dengkeng Watershed

\subsubsection{Effect of Water Avalilabilyty}

Using rainfall data in conformity with observational data can then be carried out a rainfall-runoff simulation using HEC-HMS in order to know the correlation between the simulated discharge and the observation discharge. Validation model was done by comparing the daily simulation discharge against the daily observed discharge data. The validation using RMSE was 0.71 and the average correlation value was 0.41 .

The calibration results show that there is still considerable bias between simulated discharge and observation discharge with large RMSE values and small correlations. The simulated discharge validation and observation discharge results are shown in Figure 7.

This error can be caused, among others, because in this simulation used daily rain and discharge data, while the value of hydrological parameters of watershed obtained by monthly data or a single flood. To get a better correlation, it is necessary trial and error for various conditions of hydrological parameters and data period can be used monthly or yearly data.

As previously described the validation process is used to determine changes in hydrological parameters of the watershed due to land use change. Studying the $\mathrm{CN}$ value evaluated based on the maximum discharge, the land use change is known.

To know the current availability of water, it can be evaluated based on observational discharge data. From the existing discharge data shows a tendency of decrease in average monthly discharge, as shown in Figure 8 . Meanwhile, when seen from the rain data, an increase in the amount of rain, but the amount of low discharge actually decreased. This is due to the smaller absorption of soil to store water and most of the water is wasted as surface runoff and rising flood and not reliable discharge or dependable flow. 


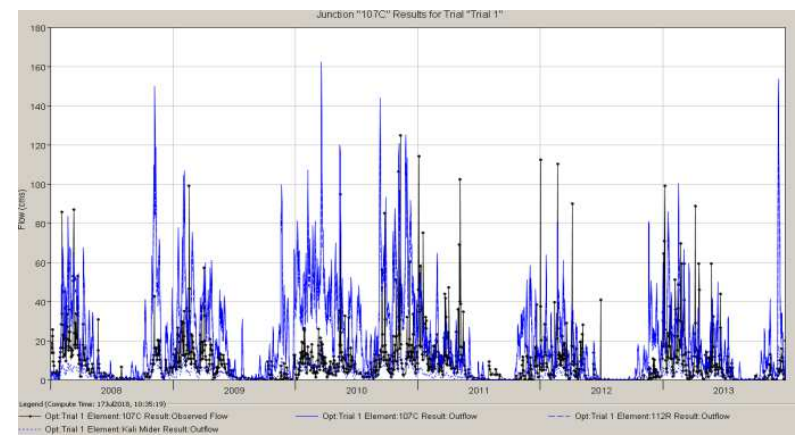

Fig. 7. Validation of simulated and observed discharge on Dengkeng Watershed

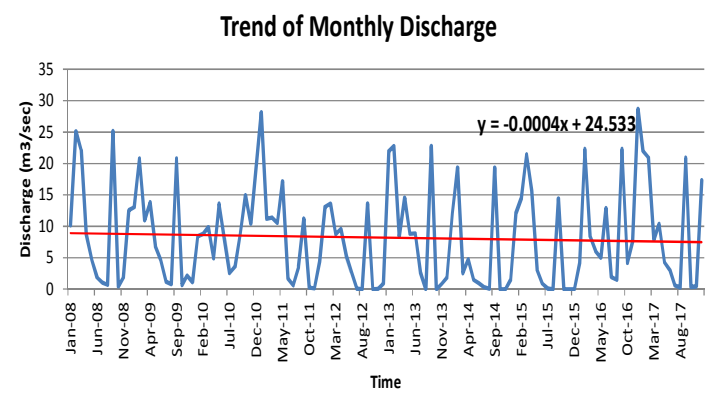

Fig. 8. Trends of Water availability on Dengkeng Watershed

\section{Conclusion}

The findings of this study indicate that climate change has occurred in the Dengkeng watershed as seen by the increase in temperature and rainfall. Increased rainfall and land use changes increase the hydrological parameters of the watershed (in this study in terms of $\mathrm{CN}$ values), that caused the increase in flood discharge.

Simulation results using daily data did not show satisfactory results, judging by the large RMSE values and small correlations. Therefore, optimization of monthly data and various hydrological parameters of land use is needed, not just $\mathrm{CN}$ value.
Referring to the existing discharge observation data, there has been a decrease in the monthly discharge which has an impact on the decreasing of reliable flow in Dengkeng watershed.

\section{Acknowledgments}

The author would like to acknowledge the Faculty of Engineering Diponegoro University for the support of this study with the acceptance of research proposal Grants Competing Fund Faculty of Engineering in budget 2018.

\section{References}

1. United Nations Framework Convention on Climate Change: Handbook. Bonn, Germany: Climate Change Secretariat (2006)

2. Nguyen Thi Ngoc Quyen, Nguyen Duy Liem, and Nguyen Kim Loi, International Soil and Water Conservation Research, Vol. 2, No. 3, pp. 74-86 (2014)

3. S. Chea and C. Oeurng, Water Utility Journal 17: 317 (2017)James Oloche OLEYIBLO, Zhi-jia LI, Water Science and Engineering, 3(1): 14-22 (2010)

4. D. S. Sampath, S. B. Weerakoon and S. Herath, ENGINEER - Vol. XLVIII, No. 01, pp. [1-9], 2015

5. Pancheewan Ponpang-Nga, Jessada Techamahasaranont, Agriculture and Natural Resources 50, 310-320, (2016)

6. Prasetyo Nugroho, Djoko Marsono, Putu Sudira, Hatma Suryatmojo, Procedia Environmental Sciences 17,256 - 262, ( 2013 )

7. Saddrodyn Motevalli, Mohammad Mahdi Hosseinzadeh, Reza Esmaili, Khabat Derafshi and Saideh Gharehchahi, Australian Journal of Basic and Applied Sciences, 6(8): 510-519 (2012)

\footnotetext{
* Corresponding author: anikharieka@gmail.com
} 